\title{
A retrospective cohort study of clinical characteristics, treatment patterns, and disease outcomes of chronic kidney disease in patients with diabetes using a Japanese claims database
}

\author{
Toru Yamazaki ( $\nabla$ toru.yamazaki@bayer.com ) \\ Bayer Yakuhin \\ Nariaki Yoshihara \\ Janssen Pharma Kabushiki Kaisha \\ Jingbo Yi \\ Syneos Health Inc \\ Yoko Tanimura \\ Bayer Yakuhin Ltd \\ Crawford Bruce \\ Syneos Health Inc
}

\section{Research article}

Keywords: Burden of disease, Chronic kidney disease, Diabetes mellitus, Mineralocorticoid receptor antagonists, Real world, Treatment patterns

Posted Date: April 23rd, 2020

DOI: https://doi.org/10.21203/rs.3.rs-23125/v1

License: (c) (1) This work is licensed under a Creative Commons Attribution 4.0 International License.

Read Full License

Version of Record: A version of this preprint was published at Value in Health on November 1st, 2019. See the published version at https://doi.org/10.1016/j.jval.2019.09.2706. 


\section{Abstract}

Objectives: The primary objective of this study was to characterize the clinical characteristics, treatment patterns, and clinical outcomes of chronic kidney disease (CKD) patients with diabetes, using a Japanese claims database and focusing on the use of mineralocorticoid receptor antagonists (MRAs) in this population in the real-world setting.

Methods: This retrospective cohort study used the Medical Data Vision database, a large, electronic health records-based claims database in Japan. The observation period was a maximum of 8 years (from 1st April 2008 to 31st August 2016). The inclusion criteria were a claim with a diagnosis of diabetes (ICD-10: E10-E14), eGFR less than $60 \mathrm{~mL} / \mathrm{min} / 1.73 \mathrm{~m}^{2}$ at the index date, and use of any antiglycemic medications within 6 months prior to the index date or during the index month. Patients who had a claim for an MRA drug after the index date were identified as the MRA subcohort. This exploratory study investigated the burden of disease in patients with CKD and diabetes, including demographics, treatments, safety, and time-to-event analysis for renal and cardiovascular-related endpoints.

Results: A total of 19,582 patients were included in the analysis, and 2,295 MRA patients were included in the subcohort. Renin-angiotensin-aldosterone system inhibitors were used at baseline by $52.3 \%$ in the overall cohort and $58.8 \%$ in the MRA subcohort. Cumulative incidences of hyperkalemia were $5.19 \%$ in the overall cohort and $7.63 \%$ in the MRA subcohort. Cox models showed that the $30-44 \mathrm{~mL} / \mathrm{min} / 1.73 \mathrm{~m}^{2}$ eGFR group had a significantly higher hazard of composite cardiovascular outcomes compared to the $45-59 \mathrm{~mL} / \mathrm{min} / 1.73 \mathrm{~m}^{2}$ group (HR, 1.22; 95\% Cl, 1.09-1.36).

Conclusion: There are residual risks for hyperkalemia and renal and cardiovascular-related events in diabetic patients with CKD in the real-world setting in Japan, even after starting treatment with steroidal MRA drugs. The unmet needs and burden of disease should be considered in future treatments for CKD patients with diabetes.

\section{Introduction}

Chronic kidney disease (CKD) is one of common complication of diabetes and the leading cause of endstage renal disease (ESRD) in the developed world. CKD with diabetes is caused by microvascular damage due to high glucose levels and defined by albuminuria, an impaired glomerular filtration rate (GFR), or both (1). At most, $42 \%$ of Japanese patients with type 2 diabetes mellitus have CKD (2), and $43.5 \%$ of hemodialysis patients is due to diabetic nephropathy (3). CKD with diabetes also has increased risks of cardiovascular disease and death, which in turn lead to higher healthcare costs (4-6). Since prevalence, severity and genetic susceptibility to CKD due to diabetes could vary by racial/ethnic group ( 7 , 8), it is worth to investigate details of the population background and their clinical outcomes in real world setting in Japan.

To prevent progression to CKD with diabetes, treatment with angiotensin-converting enzyme inhibitors (ACEis) and angiotensin II receptor blockers (ARBs) is recommended by the Kidney Disease: Improving 
Global Outcomes (KDIGO) guideline (1). Mineralocorticoid receptor antagonists (MRAs) are considered an effective treatment for CKD with diabetes (1). Spironolactone, an MRA, is known to have a beneficial effect on reducing albuminuria, although there have been no large studies reported clear clinical outcomes, such as slowing progression of CKD and decreasing mortality (9). It has, however; rather controversial label in the population with renal impairment due to the risk of hyperkalemia in Japan. Eplerenone, another MRA, has an even severer label with a contraindication for the population with renal impairment in Japan. Since ACEis and ARBs alone also tend to increase potassium levels, using MRAs with ACEis or ARBs results in a much higher rate of hyperkalemia (10). To date, however, it is unclear how these medications have been used in CKD with diabetes population in the real world, especially considering the MRA's controversial mode of action to kidney.

The objectives of this study were to characterize CKD patients with diabetes and its treatment, as well as to determine their physical burden of disease, with a focus on a subcohort of patients started on MRAs in the real-world setting in Japan.

\section{Methods}

This was a retrospective cohort study of patients with CKD and diabetes using the MDV (Medical Data Vision Co., Ltd., Tokyo, Japan) database in Japan. The MDV database is an electronic health recordsbased database of anonymized hospital data from 242 hospitals, which covers approximately $15 \%$ of acute care hospitals and data for 13.93 million people as of December $2016 ; 11.8 \%$ of patients were $0-$ 14 years of age, $46.1 \%$ were $15-64$ years of age, and $42.2 \%$ were over 65 years old. The MDV includes diagnosis-procedure combination (DPC) claims, detailed data for inpatient and outpatient encounters, drugs prescribed, diagnoses, and laboratory tests performed. Types of inpatient and outpatient encounter data include drugs (e.g., brand name, dose, days supplied), drug indications, medical practice data (e.g., date of visit, name of practice, department visited), diagnoses (e.g., date of diagnosis, date(s) of visit/inpatient stay, ICD-10 diagnosis codes), laboratory tests performed (e.g., HbA1c), and laboratory test results (when available). Other data elements in the database include patient demographics (e.g., age, sex), cost data, and hospital data, such as total number of beds.

In this study, a dataset including a maximum of 8 years of claims data for each patient, from 1st April 2008 to 31 st August 2016, was used (Fig. 1). A pre-index period was set to identify analysis populations to allow 6 months of look-back before the index date and at least a 1-year follow-up period to capture anticipated outcomes. The follow-up period was from the patients' index date to their last claim before the data end. All patients were identified in this cohort using the following criteria: patients who have a claim with a diagnosis of diabetes (ICD-10: E10-E14) with evidence of CKD (defined as eGFR less than $60 \mathrm{~mL} / \mathrm{min} / 1.73 \mathrm{~m}^{2}$ ); and patients must have been prescribed any antiglycemic medications during the pre-index period or index month. The index date was set as the first day of a CKD claim.

To investigate treatment patterns and the physical burden of disease in MRA users, a subgroup analysis was conducted. In the analysis, CKD patients with diabetes were selected into the MRA subcohort if they 
had a claim for an MRA drug during the study period any time after their index date. The index date was defined as the first MRA prescription after their CKD index date.

For both cohorts, patients were excluded from this study if any of the following criteria were met: those who did not have at least 2 claims within the 1-year follow-up period; those who did not have at least 1 claim within the 6-month pre-index period; or those with a diagnosis of ESRD, polycystic kidney disease (PKD), or immunoglobulin Class A (IGA) within the pre-index period.

Type of diabetes and other comorbidities for calculating the Modified Charlson comorbidity index were determined based on diagnosis codes (ICD-10) during the pre-index period (11) (Table S1). Patients using ARBs, ACEis, MRAs, calcium channel blockers (CCBs), or any of their combinations during the month of the index date/follow-up period were also identified based on drug codes (Table S2).

\section{Statistical analysis}

Descriptive analyses were performed using appropriate summary statistics for categorical and continuous data. Frequency tables were generated for categorical data. Selected continuous variables were categorized in a clinically meaningful way, as presented in the results.

The outcome event measures were identified from claims with an ICD-10 diagnosis code or other relevant codes (Table S3). For the time-to-event outcomes, follow-up was truncated at 1 year to ensure comparability and that all events could be captured in the enrolment period. In the cohort with CKD and diabetes, univariate analyses of time-to-event stratified by eGFR level were performed for hyperkalemia and renal and CV-related endpoints. Furthermore, Cox proportional hazards models for hyperkalemia, renal, and CV-related endpoints were conducted to evaluate the effect of eGFR level at baseline on the time to endpoint for the main cohort and the subcohort. In the models, the following other potential risk factors were included: age group ( $<50,50-59,60-69$, and $\geq 70$ years), sex, hypertension, and hyperlipidemia at baseline as covariates. Additionally, covariates that failed the proportional hazards assumptions and are also specified in the model as interaction terms with time.

All data analyses were performed using the software package SAS version 9.3 or higher (SAS Institute Inc., Cary, NC, USA). All analyses were performed in a manner consistent with the Strengthening the Reporting of Observational Studies in Epidemiology (STROBE) guidelines and applicable sections of the Consolidated Standards of Reporting Trials (CONSORT) guidelines $(12,13)$.

\section{Results}

A total of 80,348 patients had a diagnosis of diabetes and evidence of CKD. Of all patients with CKD and diabetes, 36,702 patients did not satisfy the 1-year follow-up period or the 6-month pre-index (baseline)

period. Overall, 913 patients were excluded for baseline ESRD, and 300 patients were subsequently excluded for baseline PKD and IgA neuropathy. To analyze possible patients with CKD and diabetes, 
patients without any antiglycemic drugs during the baseline period were excluded. Finally, a total of 19,582 patients with CKD and diabetes were included in the analysis.

The mean age was 70.32 (standard deviation (SD): 10.59) years in the main cohort and 71.54 (SD: 11.05$)$ years in the MRA subcohort (Table 1$)$. Overall, there were more male patients $(60.14 \%)$ than female patients in the main cohort, and most patients had type 2 diabetes $(64.49 \%$ for the main cohort and $72.29 \%$ for the MRA subcohort). For the eGFR level at baseline, the majority $(75.84 \%)$ of the main cohort had eGFR between 45 and $59 \mathrm{~mL} / \mathrm{min} / 1.73 \mathrm{~m}^{2}$, and the rest (24.16\%) had an eGFR less than $45 \mathrm{~mL} / \mathrm{min} / 1.72 \mathrm{~m}^{2}$. However, since the MRA subcohort was indexed at the MRA date, $1.18 \%$ of patients were missing the eGFR at baseline, and $19.56 \%$ of patients had eGFR $\geq 60 \mathrm{~mL} / \mathrm{min} / 1.73 \mathrm{~m}^{2}$. 
Table 1

Patients' baseline characteristics

CKD with diabetes cohort $(\mathrm{N}=$ 19,582)

MRA subcohort ( $\mathrm{N}=$ 2,295)

\begin{tabular}{|lllll|} 
& Mean & SD & Mean & SD \\
\hline Age on index date (years) & 70.32 & 10.59 & 71.54 & 11.05 \\
\hline $\begin{array}{l}\text { Modified Charlson Comorbidity } \\
\text { Index }\end{array}$ & 3.00 & 2.39 & 3.68 & 2.38 \\
\hline & $\mathbf{n}$ & $\%$ & $\mathbf{n}$ & $\%$ \\
\hline
\end{tabular}

Gender, n (\%)

Male

11,776

60.14

1,364

59.43

Female

7,806

39.86

931

40.57

Type of diabetes, $\mathbf{n}(\%)$

T1DM (E10)

436

2.23

30

1.31

T2DM (E11)

12,629

64.49

1,659

72.29

Unknown (E12, E13, E14)

11,546

58.96

1,229

53.55

$\mathrm{HbA1c}$ at baseline, $n$ (\%)

$\leq 7 \%$
$>7 \%$
None
eGFR at baseline, $\mathrm{n}(\%)$

$\geq 60 \mathrm{ml} / \mathrm{min} / 1.73 \mathrm{~m}^{2}$

8,946

45.68

976

42.53

8,607

43.95

1,074

46.80

2,029

10.36

245

10.68

$45-59 \mathrm{ml} / \mathrm{min} / 1.73 \mathrm{~m}^{2}$

14,851

0.00

449

19.56

$30-44 \mathrm{ml} / \mathrm{min} / 1.73 \mathrm{~m}^{2}$

2,822

75.84

1,134

49.41

$15-29 \mathrm{ml} / \mathrm{min} / 1.73 \mathrm{~m}^{2}$

1,062

14.41

441

19.22

$<15 \mathrm{ml} / \mathrm{min} / 1.73 \mathrm{~m}^{2}$

847

5.42

179

7.80

None

-

4.33

65

2.83

Additional Comorbidities

Hypertension

14,994

76.57

1,906

83.05

Congestive heart failure

1,755

8.96

645

28.10 


\begin{tabular}{|c|c|c|c|c|}
\hline \multirow[b]{2}{*}{ Primary hyperaldosteronism } & \multicolumn{2}{|c|}{$\begin{array}{l}\text { CKD with diabetes cohort }(\mathrm{N}= \\
\text { 19,582) }\end{array}$} & \multicolumn{2}{|c|}{$\begin{array}{l}\text { MRA subcohort }(\mathrm{N}= \\
2,295)\end{array}$} \\
\hline & 26 & 0.13 & 15 & 0.65 \\
\hline \multicolumn{5}{|l|}{ Other findings } \\
\hline Hyperkaliemia & 668 & 3.41 & 55 & 2.40 \\
\hline Edema & 775 & 3.96 & 229 & 9.98 \\
\hline
\end{tabular}

Renin-angiotensin-aldosterone system inhibitors (RAASis) were used at baseline by $52.3 \%$ of the main cohort with CKD and diabetes and $58.8 \%$ of the MRA subcohort (Fig. 2). At baseline, $33.91 \%$ of patients with CKD and diabetes did not have a treatment of interest. Even during follow-up, $28 \%$ of patients did not have any treatment (Figure S1). The most common treatment group at baseline was ARB + CCB (23.47\%), followed by ARB alone (16.48\%) and then CCB alone (10.37\%). For the MRA subcohort, since the index date was defined based on the first MRA claim, all patients had MRA-based treatment at baseline. The most common treatment group was MRA alone (27.58\%), followed by ARB + CCB + MRA (24.05\%), then ARB + MRA (17.47\%), and then CCB + MRA (13.59\%).

Table 2 shows crude event rates for hyperkalemia and renal and CV-related events during follow-up. The event rate for hyperkalemia for all patients with CKD and diabetes was 5.42 per 100 person-years (PY), and 8.06 per $100 \mathrm{PY}$ for the MRA subcohort. Cumulative incidences during the observation period were $5.19 \%$ for the main cohort and $7.63 \%$ for the MRA subcohort. When stratified by eGFR at baseline in the main cohort, the event rate for hyperkalemia was lowest in the $45-59 \mathrm{~mL} / \mathrm{min} / 1.73 \mathrm{~m}^{2}$ group $(2.23$ per $100 \mathrm{PY}$ ), and it jumped to 31.1 per $100 \mathrm{PY}$ in the lower eGFR groups. For renal failure, the event rate for all patients was 13.39 per $100 \mathrm{PY}$. When stratified by eGFR at baseline, the event rate for renal failure was again lowest in the $45-59 \mathrm{~mL} / \mathrm{min} / 1.73 \mathrm{~m}^{2}$ group. The event rate for renal events increased as the eGFR level decreased, and this pattern was observed across all renal-related events. 
Table 2

Crude event rates for hyperkalemia and renal and cardiovascular events CKD with diabetes cohort

MRA

subcohort

All

eGFR 45-

$59 *$

19,582

14,851

326

$2.23(2$

2.49)

(5.09),

$5.76)$

$(95 \% \mathrm{Cl})$

1,016

221

8.34 (7.31,

9.52)

eGFR 30-

eGFR 15-

29*

2,822

1,062

847

2,295

eGFR $<15 * \quad$ All

175

31.1 (27.56,

35.11)

207

8.06 (6.95,

31.13

(27.16,

35.67)

\section{Renal failure}

$\mathrm{N}$ events

2,358

654

576

640

488

409

Event Rate

13.39

$(95 \% \mathrm{Cl})$

(12.86,

13.94)

4.56 (4.22,

4.92)

24.38

(22.47,

127.25

(117.77,

26.46)

137.5)

123.05

(112.6,

134.47)

20.64

(18.73,

22.74)

\section{Reduction of} eGFR $\geq 40 \%$

N events
$\begin{aligned} & \text { Event Rate } \\ & (95 \% \mathrm{Cl})\end{aligned}$
$\begin{aligned} & \text { Composite CV } \\ & \text { events }\end{aligned}$

$\mathrm{N}$ events

1,643

882

326

224

211

466

\subsection{6}

$(8.44,9.3)$

6.16 (5.77,

12.44

(11.16,

13.86)

24.05 (21.1,

27.41)

31.06

(27.14,

35.54)

23.48

(21.44,

25.71)

$\begin{array}{lllllll}\text { Event Rate } & 28.77 & 25.67 & 37.57 & 45.14 & 38.09 & 50.74 \\ (95 \% \mathrm{Cl}) & (27.95, & (24.79, & (35.07, & (40.67, & (33.63, & (47.43, \\ & 29.62) & 26.59)^{\prime} & 40.25)^{\prime} & 50.1) & 43.15)^{\prime} & 54.29)^{\prime}\end{array}$

Myocardial

infarction

$\begin{array}{lllllll}\text { N events } & 513 & 371 & 81 & 32 & 29 & 107 \\ \text { Event Rate } & 2.68 & 2.55(2.31, & 2.94(2.36, & 3.08(2.18, & 3.52(2.45, & 4.85(4.01, \\ (95 \% \mathrm{Cl}) & (2.46, & 2.83) & 3.65) & 4.36) & 5.07) & 5.86)\end{array}$

* Unit: $\mathrm{mL} / \mathrm{min} / 1.73 \mathrm{~m}^{2}$; Cl: Confidence Interval; CV: Cardiovascular; HF: Heart Failure.

Composite CV event: the first event among myocardial infarction, Stroke, or hospitalization for heart failure 


\section{CKD with diabetes cohort}

MRA

subcohort

\section{Stroke}

\begin{tabular}{|c|c|c|c|c|c|c|}
\hline $\mathrm{N}$ events & 2,963 & 2,140 & 500 & 178 & 145 & 343 \\
\hline $\begin{array}{l}\text { Event Rate } \\
(95 \% \mathrm{Cl})\end{array}$ & $\begin{array}{l}17.48 \\
(16.86, \\
18.12)\end{array}$ & $\begin{array}{l}16.54 \\
(15.85, \\
17.25)\end{array}$ & $\begin{array}{l}21.03 \\
(19.26, \\
22.95)\end{array}$ & $\begin{array}{l}19.61 \\
(16.93, \\
22.71)\end{array}$ & $\begin{array}{l}20.09 \\
(17.07, \\
23.64)\end{array}$ & $\begin{array}{l}17.12 \\
(15.4 \\
19.03)\end{array}$ \\
\hline
\end{tabular}

\section{Hospitalization}

for HF

$\begin{array}{lllllll}\text { N events } & 1,515 & 886 & 327 & 195 & 107 & 537 \\ \text { Event Rate } & 8.17 & 6.22(5.82, & 12.58 & 20.99 & 13.8(11.42, & 27.59 \\ (95 \% \mathrm{Cl}) & (7.77, & 6.64) & (11.28, & (18.24, & 16.68) & (25.35, \\ & 8.59) & & 14.02) & 24.16) & & 30.03)^{\prime}\end{array}$

* Unit: $\mathrm{mL} / \mathrm{min} / 1.73$ m²; Cl: Confidence Interval; CV: Cardiovascular; HF: Heart Failure.

Composite CV event: the first event among myocardial infarction, Stroke, or hospitalization for heart failure

In contrast, for CV-related events, the event rate did not show an evident pattern among the different eGFR groups in the main cohort. In general, the CV-related event rate was lowest for the 45$59 \mathrm{~mL} / \mathrm{min} / 1.73 \mathrm{~m}^{2}$ group, but it varied across the other stratifications. In particular, there were higher risks for hospitalization for heart failure and composite CV-related events in the $15-29 \mathrm{~mL} / \mathrm{min} / 1.73 \mathrm{~m}{ }^{2}$ group. All event rates for renal and CV-related events were relatively higher in the MRA subcohort.

Table 3 shows the hazard ratios (HRs) of the eGFR level at baseline for renal and CV-related events in the entire cohort with CKD and diabetes. Cox regression models showed that the adjusted HRs of renal events were much higher as the baseline eGFR decreased. For MI and stroke, the risk of eGFR at baseline was not significant after adjusting for potential confounders across all stratified groups. However, the hazard of hospitalization for heart failure was the highest in the $15-29 \mathrm{~mL} / \mathrm{min} / 1.73 \mathrm{~m}^{2}$ group (HR, 3.13; 95\% confidence interval (CI), 2.68-3.66), even after adjusting for covariates. For the composite CV-related outcome, the 30-44 mL/min/1.73 $\mathrm{m}^{2}$ eGFR group had a higher hazard of the composite CV-related outcome compared to the $45-59 \mathrm{~mL} / \mathrm{min} / 1.73 \mathrm{~m}^{2}$ eGFR group (HR, 1.22; $95 \% \mathrm{Cl}, 1.09-1.36$ ), although significant differences in HRs were not observed in the other strata. 
Table 3

Cox regression for hyperkalemia and renal and cardiovascular events in the entire cohort with CKD and diabetes

\begin{tabular}{|c|c|c|c|c|}
\hline & $\begin{array}{l}\text { eGFR 45- } \\
59^{*}\end{array}$ & eGFR $30-44^{*}$ & eGFR 15-29* & eGFR $<15^{*}$ \\
\hline At risk & 14,851 & 2,822 & 1,062 & 847 \\
\hline \multicolumn{5}{|l|}{ Hyperkalemia } \\
\hline $\begin{array}{l}\text { Hazard ratio }(95 \% \\
\mathrm{Cl})\end{array}$ & 1.00 (ref) & $\begin{array}{l}3.50(2.94 \\
4.15)\end{array}$ & $\begin{array}{l}11.81(10.03 \\
13.91)\end{array}$ & $\begin{array}{l}\text { 12.17 (10.21, } \\
14.51)\end{array}$ \\
\hline \multicolumn{5}{|l|}{ Renal failure } \\
\hline $\begin{array}{l}\text { Hazard ratio }(95 \% \\
\mathrm{Cl})\end{array}$ & 1.00 (ref) & $\begin{array}{l}4.92(4.40 \\
5.51)\end{array}$ & $\begin{array}{l}18.90(16.92, \\
21.10)\end{array}$ & $\begin{array}{l}18.28(16.23 \\
20.59)\end{array}$ \\
\hline \multicolumn{5}{|l|}{$\begin{array}{l}\text { Composite CV } \\
\text { events }\end{array}$} \\
\hline $\begin{array}{l}\text { Hazard ratio }(95 \% \\
\mathrm{Cl})\end{array}$ & 1.00 (ref) & $\begin{array}{l}1.22(1.09 \\
1.36)\end{array}$ & $1.13(0.95,1.34)$ & $1.00(0.81,1.23)$ \\
\hline \multicolumn{5}{|l|}{$\begin{array}{l}\text { Myocardial } \\
\text { infarction }\end{array}$} \\
\hline $\begin{array}{l}\text { Hazard ratio }(95 \% \\
\mathrm{Cl})\end{array}$ & 1.00 (ref) & $\begin{array}{l}1.09(0.86 \\
1.39)\end{array}$ & $1.12(0.78,1.60)$ & $1.31(0.90,1.91)$ \\
\hline \multicolumn{5}{|l|}{ Stroke } \\
\hline $\begin{array}{l}\text { Hazard ratio }(95 \% \\
\mathrm{Cl})\end{array}$ & 1.00 (ref) & $\begin{array}{l}1.12(0.98, \\
1.28)\end{array}$ & $0.91(0.73,1.13)$ & $0.88(0.68,1.14)$ \\
\hline \multicolumn{5}{|l|}{$\begin{array}{l}\text { Hospitalization for } \\
\text { HF }\end{array}$} \\
\hline $\begin{array}{l}\text { Hazard ratio }(95 \% \\
\mathrm{Cl})\end{array}$ & 1.00 (ref) & $\begin{array}{l}1.91(1.68, \\
2.17)\end{array}$ & $3.132 .68,3.66)$ & $2.25(1.84,2.76)$ \\
\hline
\end{tabular}

Table 4 shows the HRs of hyperkalemia and renal and CV-related events in the MRA subcohort. Adjusted HRs of hyperkalemia and renal events were higher as baseline eGFR decreased, as in the main cohort. For hospitalization for heart failure, the HRs were still high across the stratified groups, and the highest in the $15-29 \mathrm{~mL} / \mathrm{min} / 1.73 \mathrm{~m}^{2}$ group (HR, 2.55; $\left.95 \% \mathrm{Cl}, 1.96-3.30\right)$. On the other hand, significant differences in HRs were not observed for composite $\mathrm{CV}, \mathrm{Ml}$, and stroke events, except that the HR for MI was lower in the $30-44 \mathrm{~mL} / \mathrm{min} / 1.73 \mathrm{~m}^{2}$ group. 
Table 4

Cox regression for hyperkalemia and renal and cardiovascular events in the MRA subcohort

\begin{tabular}{|c|c|c|c|c|c|}
\hline & $\begin{array}{l}\text { eGFR } 60 \geq^{*} \text { or } \\
\text { None }\end{array}$ & $\begin{array}{l}\text { eGFR 45- } \\
59 *\end{array}$ & $\begin{array}{l}\text { eGFR 30- } \\
44^{*}\end{array}$ & eGFR 15-29* & eGFR $<15^{*}$ \\
\hline At risk & 476 & 1,134 & 441 & 179 & 65 \\
\hline \multicolumn{6}{|l|}{ Hyperkalemia } \\
\hline $\begin{array}{l}\text { Hazard ratio } \\
(95 \% \mathrm{Cl})\end{array}$ & $\begin{array}{l}0.73(0.42 \\
1.25)\end{array}$ & 1.00 (ref) & $\begin{array}{l}1.84(1.22, \\
2.77)\end{array}$ & $\begin{array}{l}5.75(3.85 \\
8.57)\end{array}$ & $\begin{array}{l}6.37(3.68, \\
11.00)\end{array}$ \\
\hline \multicolumn{6}{|l|}{ Renal failure } \\
\hline $\begin{array}{l}\text { Hazard ratio } \\
(95 \% \mathrm{Cl})\end{array}$ & $\begin{array}{l}0.24(0.08 \\
0.67)\end{array}$ & 1.00 (ref) & $\begin{array}{l}2.57(1.52, \\
4.35)\end{array}$ & $\begin{array}{l}7.36(4.42 \\
12.26)\end{array}$ & $\begin{array}{l}8.20(4.24 \\
15.86)\end{array}$ \\
\hline \multicolumn{6}{|c|}{$\begin{array}{l}\text { Composite CV } \\
\text { events }\end{array}$} \\
\hline $\begin{array}{l}\text { Hazard ratio } \\
(95 \% \mathrm{Cl})\end{array}$ & $\begin{array}{l}0.73(0.51 \\
1.05)\end{array}$ & 1.00 (ref) & $\begin{array}{l}0.92(0.66 \\
1.28)\end{array}$ & $\begin{array}{l}0.90(0.56 \\
1.43)\end{array}$ & $\begin{array}{l}0.84(0.38 \\
1.84)\end{array}$ \\
\hline \multicolumn{6}{|l|}{$\begin{array}{l}\text { Myocardial } \\
\text { infarction }\end{array}$} \\
\hline $\begin{array}{l}\text { Hazard ratio } \\
(95 \% \mathrm{Cl})\end{array}$ & $\begin{array}{l}0.33(0.11 \\
0.93)\end{array}$ & 1.00 (ref) & $\begin{array}{l}0.17(0.04 \\
0.68)\end{array}$ & $\begin{array}{l}0.31(0.06 \\
1.54)\end{array}$ & $\begin{array}{l}0.38(0.03 \\
4.97)\end{array}$ \\
\hline \multicolumn{6}{|l|}{ Stroke } \\
\hline $\begin{array}{l}\text { Hazard ratio } \\
(95 \% \mathrm{Cl})\end{array}$ & $\begin{array}{l}0.91(0.68 \\
1.22)\end{array}$ & 1.00 (ref) & $\begin{array}{l}1.06(0.80 \\
1.40)\end{array}$ & $\begin{array}{l}1.37(0.96 \\
1.96)\end{array}$ & $\begin{array}{l}0.96(0.49 \\
1.87)\end{array}$ \\
\hline \multicolumn{6}{|c|}{$\begin{array}{l}\text { Hospitalization } \\
\text { for HF }\end{array}$} \\
\hline $\begin{array}{l}\text { Hazard ratio } \\
(95 \% \mathrm{Cl})\end{array}$ & $\begin{array}{l}0.96(0.75 \\
1.22)\end{array}$ & 1.00 (ref) & $\begin{array}{l}1.36(1.09 \\
1.71)\end{array}$ & $\begin{array}{l}2.55(1.96 \\
3.30)\end{array}$ & $\begin{array}{l}1.96(1.26 \\
3.04)\end{array}$ \\
\hline
\end{tabular}

\section{Discussion}

This study examined the burden of disease, including demographics, treatment patterns, and time-toevent analyses, of CKD patients with diabetes using a Japanese claims database. A subgroup analysis of patients using MRAs was also conducted to investigate their treatment characteristics and burden of illness. To the best of our knowledge, this is the first large cohort study to assess the burden of disease of CKD patients with diabetes in a real-world setting in Japan. 
Renal and CV-related events are still a burden to patients with CKD and diabetes, and the highest risks for CV-related outcomes were observed in patients with low and middle eGFR stages at baseline (15-29 and $30-44 \mathrm{~mL} / \mathrm{min} / 1.73 \mathrm{~m}^{2}$ groups) in the present study. However, a meta-analysis of population cohorts by KDIGO showed a linear relationship between lower eGFR level and risk of CV mortality; namely CKD patients with an eGFR level less than $15 \mathrm{~mL} / \mathrm{min} / 1.73 \mathrm{~m}^{2}$ had the highest risk of CV mortality (HR, 3.14; $95 \% \mathrm{Cl}, 2.39-4.13$ ) compared to eGFR $95 \mathrm{~mL} / \mathrm{min} / 1.73 \mathrm{~m}^{2}$ (14). One possible explanation of the difference between previous studies and the present one is that patients who have any potential risks of CV diseases with a lower eGFR level might be transferred to other hospitals for dialysis treatment, and therefore information on events, particularly among the stratified group of eGFR $<15 \mathrm{~mL} / \mathrm{min} / 1.73 \mathrm{~m}^{2}$, could not be captured due to the characteristics of the MDV database (15).

The prevalence and incidence of hyperkalemia appeared to be relatively high, particularly among MRA users, in the present study population (5.19\% for the entire cohort and $7.63 \%$ for the MRA cohort). A review of hyperkalemia estimated the prevalence to range from $2.6-3.5 \%$ in large samples from elderly patients in Canada or in US veterans; however, the frequency of hyperkalemia may vary according to the case mix of the studied population, such as a CKD or DKD population, and by eGFR level, ranging from $1.9-38.4 \%$ (16). For example, a recent retrospective cohort study of CKD patients in a hospital setting in Japan showed that $12.3 \%$ of non-dialysis CKD patients treated with RAASis $(n=986)$ developed hyperkalemia (17). These findings indicate a large difference in absolute risk of hyperkalemia between different studies/populations. A more robust estimate awaits larger observational studies in the target population.

Subgroup analysis indicated that there are residual risks for renal and CV-related events even after initiation of treatment with steroidal MRA drugs in patients with CKD and diabetes. A recent KDIGO guideline on DKD recommended blockade of the renin-angiotensin-aldosterone system and control of blood pressure to reduce CV risks via both atherosclerotic and nonatherosclerotic mechanisms (18). Since mineralocorticoid receptor blockade also has proven clinical efficacy in patients with heart failure (HF) with reduced ejection fraction, arterial hypertension, and CKD, steroidal MRAs could be used on top of RAASi treatment or alone as a critical therapy especially for patients with HF (19). However, the present results did not show any CV risk reductions after initiation of steroidal MRA treatment in patients with CKD and diabetes. It is possible that, although MRA was prescribed particularly for patients with more comorbidity at baseline, the treatment effect might be limited in the MRA subcohort. Moreover, use of steroidal MRAs could induce severe hyperkalemia, gynecomastia, etc. (19) (20). Therefore, a new approach may be needed for CKD and diabetes patients for CV risk prevention and fewer safety concerns.

Several limitations of this study warrant mention. First, patients extracted from the MDV database might not be fully representative of patients with CKD and diabetes in Japan, since the MDV database consists of hospitals and their associated clinics, not independent clinics. However, the MDV population closely matches the general Japanese population in terms of age and sex distribution. Second, the MDV database does not allow follow-up of patients who changed hospitals (15). Therefore, if a patient seeks care at another center, they cannot be tracked. Additionally, each hospital uses its own unique identifier, 
so even if the patient receives care at another participating hospital, there is no way to link their patient number, so that they will appear as multiple patients. Considering the nature of the MDV database, at least one claim each 6 months was included, assuming that the patients would be continuously receiving treatment at that center. Third, outcomes of interests were not validated but defined only by ICD-10 codes in the present study. Data on urinary albumin and biopsy were also not available for confirmation of the CKD diagnosis in diabetic patients. Therefore, all events may not be captured or might be under- or overestimated. Fourth, the exploratory subgroup analysis should be carefully interpreted due to the small sample size. Finally, some HRs in the Cox models may be difficult to interpret due to violation of the proportional-hazards assumption, although any violated variables were specified as time-covariate interaction terms in the model.

In conclusion, the results from this retrospective cohort study showed that renal and CV-related events are still a burden to patients with CKD and diabetes, and that there are residual risks of hyperkalemia and renal and CV events even after initiation of treatment by steroidal MRA drugs in the real-world setting in Japan. Therefore, a new approach may be needed for CKD and diabetes patients to decrease CV risk with fewer safety concerns.

\section{Abbreviations}

ACE

Angiotensin-converting enzyme

ARB

Angiotensin receptor II blocker

CCB

Calcium channel blocker

$\mathrm{Cl}$

Confidence interval

CKD

Chronic kidney disease

CV

Cardiovascular

DPC

Diagnosis procedure combination

DKD

Diabetic kidney disease

ESRD

End-stage renal disease

HF

Heart failure

$\mathrm{HR}$

Hazard ratio 
ICD-10

International Classification of Diseases, Tenth Revision, Clinical Modification

IGA

Immunoglobulin class A

KDIGO

Kidney Disease:Improving Global Outcomes

MDV

Medical Data Vision

MRA

Mineralocorticoid receptor antagonist

PY

Person-years

PKD

Polycystic kidney disease

RAASi

Renin-angiotensin-aldosterone system inhibitors

\section{Declarations}

\section{Ethics approval and consent to participate}

The study protocol was approved by the Ethics Committee of "Clinical Research Promotion Network Japan" on 21st December 2017 (CRPNJSOP-4-5). This study was designed, implemented and reported in accordance with the "Guidelines for Good Pharmacoepidemiology Practices of the International Society for Pharmacoepidemiology (GPP)", the "Strengthening the Reporting of Observational Studies in Epidemiology (STROBE)" guidelines, and with the ethical principles laid down in the Declaration of Helsinki. As this is a study based on secondary use of data, informed consent was not necessary.

\section{Consent for publication}

Not applicable.

\section{Availability of data and materials}

The data that support the findings of this study are available from MDV (Medical Data Vision Co., Ltd., Tokyo, Japan), but restrictions apply to the availability of these data, which were used under license for the current study, and so are not publicly available. Data are however available from the corresponding author on reasonable request with the permission of MDV. 


\section{Competing interests}

TY and YT are employees of Bayer Yakuhin, Ltd. Japan. NY was an employee of Bayer Yakuhin, Ltd. Japan at the time of this study. BC and JY are employees of Syneos Health.

\section{Funding}

The conduct of the study and preparation of the manuscript were supported financially by Bayer Yakuhin, Ltd. Japan. Beyond the named authors who are employees who did meet authorship criteria, the funding body was not involved in the design of the study, the collection, analysis/interpretation of data, or writing the manuscript.

\section{Authors' contributions}

TY contributed to developing the study design, the study execution, review of the analysis, interpretation of the findings, and preparation of the manuscript. NY initiated and contributed to the study set-up, concept and its execution, review of the analysis, interpretation of the findings, and review of the manuscript. JY contributed to developing the study design, analyzing the data, summarizing the results, interpreting the findings, and review of the manuscript. YT contributed to the study concept, review of the analysis, interpretation of the findings, and review of the manuscript. BC contributed to developing the study design, review of the analysis, interpretation of the findings, and review of the manuscript. All authors read and approved the final manuscript.

\section{Acknowledgements}

Not applicable.

\section{References}

1. Kdoqi KDOQI. Clinical Practice Guideline and Clinical Practice Recommendations for anemia in chronic kidney disease: 2007 update of hemoglobin target. Am J Kidney Dis. 2007;50(3):471-530.

2. Yokoyama H, Kawai K, Kobayashi M, Japan Diabetes Clinical Data Management Study G. Microalbuminuria is common in Japanese type 2 diabetic patients: a nationwide survey from the Japan Diabetes Clinical Data Management Study Group (JDDM 10). Diabetes Care. 2007;30(4):98992.

3. Nakai S, Hanafusa N, Masakane I, Taniguchi M, Hamano T, Shoji T, et al. An overview of regular dialysis treatment in Japan (as of 31 December 2012). Ther Apher Dial. 2014;18(6):535-602.

4. de Boer IH, Katz R, Cao JJ, Fried LF, Kestenbaum B, Mukamal K, et al. Cystatin C, albuminuria, and mortality among older adults with diabetes. Diabetes Care. 2009;32(10):1833-8. 
5. Ninomiya T, Perkovic V, de Galan BE, Zoungas S, Pillai A, Jardine M, et al. Albuminuria and kidney function independently predict cardiovascular and renal outcomes in diabetes. J Am Soc Nephrol. 2009;20(8):1813-21.

6. US Renal Data System 2016 Annual Data Report:

Saran R, Robinson B, Abbott KC, Agodoa LY, Albertus P, Ayanian J, et al. US Renal Data System 2016 Annual Data Report: Epidemiology of Kidney Disease in the United States. Am J Kidney Dis. 2017;69(3 Suppl 1):A7-8.

7. Mooyaart AL, Valk EJ, van Es LA, Bruijn JA, de Heer E, Freedman BI, et al. Genetic associations in diabetic nephropathy: a meta-analysis. Diabetologia. 2011;54(3):544-53.

8. Muthuppalaniappan VM, Yaqoob MM. Ethnic/Race Diversity and Diabetic Kidney Disease. J Clin Med. 2015;4(8):1561-5.

9. Hou J, Xiong W, Cao L, Wen X, Li A. Spironolactone Add-on for Preventing or Slowing the Progression of Diabetic Nephropathy: A Meta-analysis. Clin Ther. 2015;37(9):2086-103. e10.

10. Desai AS, Vardeny O, Claggett B, McMurray JJ, Packer M, Swedberg K, et al. Reduced Risk of Hyperkalemia During Treatment of Heart Failure With Mineralocorticoid Receptor Antagonists by Use of Sacubitril/Valsartan Compared With Enalapril: A Secondary Analysis of the PARADIGM-HF Trial. JAMA Cardiol. 2017;2(1):79-85.

11. Quan H, Li B, Couris CM, Fushimi K, Graham P, Hider P, et al. Updating and validating the Charlson comorbidity index and score for risk adjustment in hospital discharge abstracts using data from 6 countries. Am J Epidemiol. 2011;173(6):676-82.

12. von Elm E, Altman DG, Egger M, Pocock SJ, Gotzsche PC, Vandenbroucke JP, et al. The Strengthening the Reporting of Observational Studies in Epidemiology (STROBE) statement: guidelines for reporting observational studies. Epidemiology. 2007;18(6):800-4.

13. Schulz KF, Altman DG, Moher D, Group C. CONSORT 2010 statement: updated guidelines for reporting parallel group randomised trials. BMJ. 2010;340:c332.

14. Prognosis CKidneyD, Matsushita C, van der Velde K, Astor M, Woodward BC, Levey M. AS, et al. Association of estimated glomerular filtration rate and albuminuria with all-cause and cardiovascular mortality in general population cohorts: a collaborative meta-analysis. Lancet. 2010;375(9731):2073-81.

15. Wake M, Onishi Y, Guelfucci F, Oh A, Hiroi S, Shimasaki Y, et al. Treatment patterns in hyperlipidaemia patients based on administrative claim databases in Japan. Atherosclerosis. 2018;272:145-52.

16. Kovesdy CP. Epidemiology of hyperkalemia: an update. Kidney Int Suppl (2011). 2016;6(1):3-6.

17. Saito Y, Yamamoto H, Nakajima H, Takahashi O, Komatsu Y. Incidence of and risk factors for newly diagnosed hyperkalemia after hospital discharge in non-dialysis-dependent CKD patients treated with RAS inhibitors. PLoS One. 2017;12(9):e0184402.

18. Perkovic V, Agarwal R, Fioretto P, Hemmelgarn BR, Levin A, Thomas MC, et al. Management of patients with diabetes and CKD: conclusions from a "Kidney Disease: Improving Global Outcomes" (KDIGO) Controversies Conference. Kidney Int. 2016;90(6):1175-83. 
19. Kolkhof P, Nowack C, Eitner F. Nonsteroidal antagonists of the mineralocorticoid receptor. Curr Opin Nephrol Hypertens. 2015;24(5):417-24.

20. Capelli I, Gasperoni L, Ruggeri M, Donati G, Baraldi O, Sorrenti G, et al. New mineralocorticoid receptor antagonists: update on their use in chronic kidney disease and heart failure. $\mathrm{J}$ Nephrol. 2020;33(1):37-48.

\section{Figures}

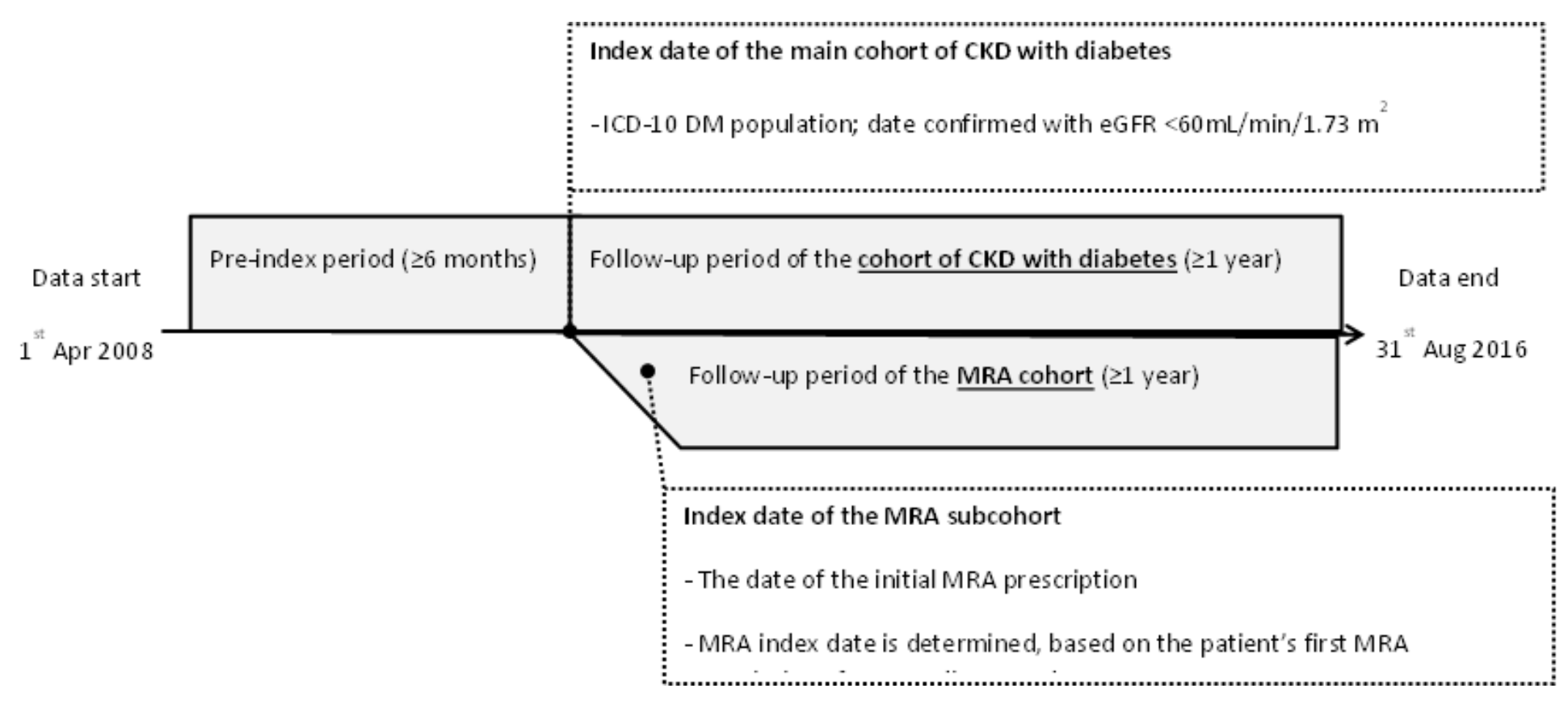

\section{Figure 1}

Study design 


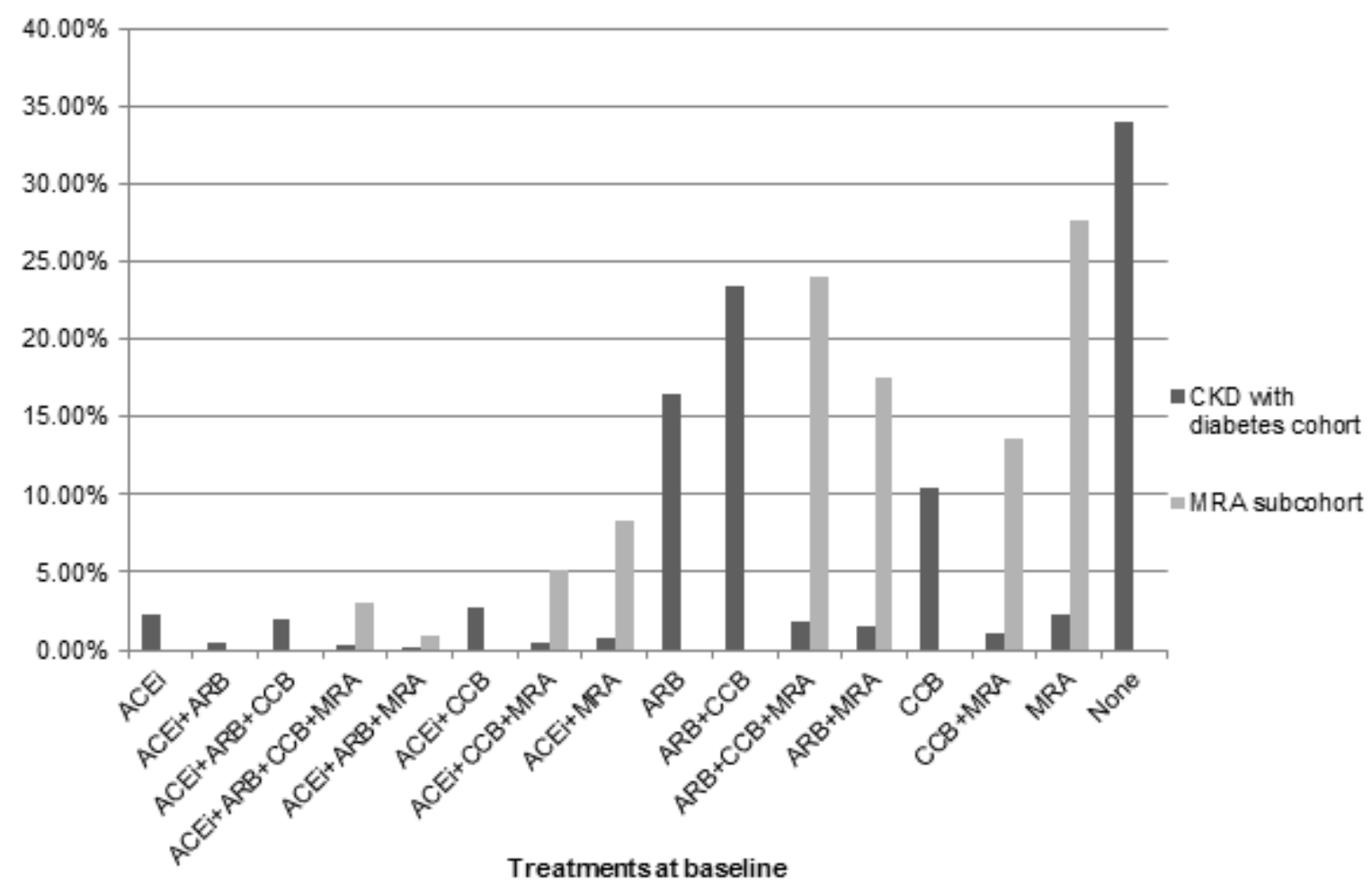

Figure 2

Anti-hypertensive agent treatment patterns in CKD patients with diabetes at baseline

\section{Supplementary Files}

This is a list of supplementary files associated with this preprint. Click to download.

- supplementaryBMC.docx 